\title{
A PHOTOELECTRIC INVESTIGATION OF THE DOUBLE CEPHEID CE CAS
}

\author{
OTTO G. FRANZ
}

Lowell Observatory, Flagstaff, Ariz. 86001, U.S.A.

\begin{abstract}
A photoelectric area scanner (Franz, 1970) was used to carry out photometry of the separate components of the double Cepheid CE Cas, a binary of 2.5" separation located in NGC 7790. CE Cas A was found to undergo rapid fluctuations as well as a slow change of its brightness near minimum phase, while its brightness at maximum has remained the same over more than $10 \mathrm{yr}$. The absence of the effect from the observations of CE Cas B and evidence for its presence in earlier observations by Sandage and Tammann (1969) serve to establish the reality of this phenomenon. Manifestation of this effect during early phases of this investigation had led to the erroneous conclusion that CE Cas A had undergone a significant change of period in recent years (Franz, 1972).
\end{abstract}

\section{Acknowledgement}

This work has been supported by the National Science Foundation.

\section{References}

Franz, O. G.: 1970, Lowell Obs. Bull., No. 154, 191.

Franz, O. G.: 1972, Bull. Am. Astron. Soc. 4, 329.

Sandage, A. and Tammann, G. A.: 1969, Astrophys. J. 157, 683.

\section{DISCUSSION}

$F$. van ' $t$ Veer: Do you know the period of the orbital revolution of the $A-B$ system?

$O$. G. Franz: More than $100000 \mathrm{yr}$, probably. 